\title{
Structure-Dependent Dissolution and Restructuring of Calcite Surfaces by Organophosphonates
}

\author{
Martin Nalbach, ${ }^{* \dagger \odot}$ Argyri Moschona, ${ }^{\ddagger}$ Konstantinos D. Demadis, ${ }^{\ddagger}$ Stefanie Klassen, ${ }^{\dagger}$ Ralf Bechstein, ${ }^{\dagger}$ \\ and Angelika Kühnle

\begin{abstract}
${ }^{\dagger}$ Institute of Physical Chemistry, Johannes Gutenberg University Mainz, Duesbergweg 10-14, 55099 Mainz, Germany
${ }^{\ddagger}$ Crystal Engineering, Growth and Design Laboratory, Department of Chemistry, University of Crete, Voutes Campus, Heraklion, Crete, GR-71003, Greece
\end{abstract}

\begin{abstract}
Organophosphonates are well-known to strongly interact with the surfaces of various minerals, such as brucite, gypsum, and barite. In this work, we study the influence of six systematically varied organophosphonate molecules (tetraphosphonates and diphosphonates) on the dissolution process of the (10.4) surface of calcite. In order to pursue a systematic study, we have selected organophosphonates that exhibit similar structural features, but also systematic architectural differences. The effect of this class of additives on the dissolution process of the calcite (10.4) surface is evaluated using in situ dynamic atomic force microscopy. For all of the six organophosphonate derivatives, we observe a pronounced restructuring of the (10.4) cleavage plane

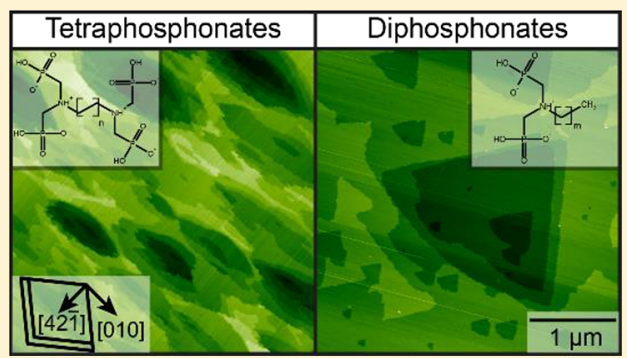
of calcite, demonstrated by the formation of characteristically shaped etch pits. To elucidate their specific influence on the dissolution process of calcite (10.4), we vary systematically the number of functional end groups (two for the tetraphosphonates and one for the diphosphonates), the spacing between the functional ends through separating methylene groups (2, 6, and 12), as well as the $\mathrm{pH}$ of the solution (ranging from 2.6 up to 11.7). For each of the two groups of the organophosphonate derivatives, we observe the very same formation of etch pits (olive-shaped for the tetraphosphonate and triangular-shaped for the diphosphonate molecules), respectively. This finding indicates that the number of functional ends decisively determines the resulting calcite (10.4) surface morphology, whereas the size of the organophosphonate molecule within one group seems not to play any important role. For all of the molecules, the restructuring process of calcite (10.4) is qualitatively independent of the $\mathrm{pH}$ of the solution and, therefore, independent of the protonation/deprotonation states of the molecules. Our results reveal a general property of organophosphonate derivatives to induce surface restructuring of the calcite (10.4), which seems to be very robust against variations in both, different molecular structures and different protonation/deprotonation states.
\end{abstract}

\section{INTRODUCTION}

Organophosphonic acids are molecules that possess a direct phosphorus-carbon $(\mathrm{P}-\mathrm{C})$ bond between the phosphonate tetrahedral moiety and the organic part, in contrast to organophosphates, which possess a phosphorus-oxygen-carbon ( $\mathrm{P}-$ $\mathrm{O}-\mathrm{C})$ linkage. ${ }^{1}$ The presence of the robust $\mathrm{P}-\mathrm{C}$ bond (dissociation energy of $513 \mathrm{~kJ} / \mathrm{mol}^{2}$ ) renders these molecules resistant to hydrolysis and thermal decomposition. ${ }^{3}$ More specifically, all organophosphonates studied here belong to the aminomethylene-phosphonate family, bearing the aminomethylenephosphonate $\left(-\mathrm{N}^{+}(\mathrm{H})-\mathrm{CH}_{2}-\mathrm{PO}_{3} \mathrm{H}^{-}\right)$zwitterionic moiety. Due to the high affinity of the phosphonate group toward metal ions and mineral surfaces, organophosphonates have been used extensively in the construction of metalorganic frameworks, ${ }^{4}$ as scale growth inhibitors, ${ }^{5}$ and they have been studied intensively on various mineral surfaces like calcite, ${ }^{6-8}$ gypsum, ${ }^{9}$ barium sulfate, ${ }^{10}$ and brucite. ${ }^{11}$

Organic additives are known to alter the surface morphology of minerals in various ways, e.g., affecting dissolution and growth, as well as inducing a restructuring of the surface. ${ }^{12-18}$ For example, ancient polysaccharide ${ }^{16}$ adsorbs with a high affinity to calcite step edges, resulting in a modified and characteristically restructured surface morphology during both, calcite dissolution and calcite growth.

Here, we study the influence of three tetraphosphonate and three diphosphonate molecules on the dissolution process of the calcite (10.4) surface, the thermodynamically most stable cleavage plane of calcite (Figure 1a). The schematic structures for each family of organophosphonates are shown in Figure $1 b, c$; the detailed molecule names, abbreviations, and schematic structures are given in Table 1.

For our studies, we focus on two principal structural differences of the additive molecules. On the one hand, within each group of organophosphonate molecules, we study the influence of the spacing between the functional ends through a variation of the number of methylene $\left(-\mathrm{CH}_{2}-\right)$ groups. We compare molecules with only 2 separating methylene groups (EDTMP-C ${ }_{2}$-T and EABMP-C $\left.{ }_{2}-\mathrm{D}\right)$ ), 6 (HDTMP-C (HD $_{6}$-T and HABMP-C $_{6}-\mathrm{D}$ ), and 12 (DDTMP-C 12 -T and DABMP-C $\left.12-\mathrm{D}\right)$. On the other hand, we compare for each of the three pairs of

Received: July 11, 2017

Revised: September 26, 2017

Published: October 2, 2017 
(a) Calcite (10.4)

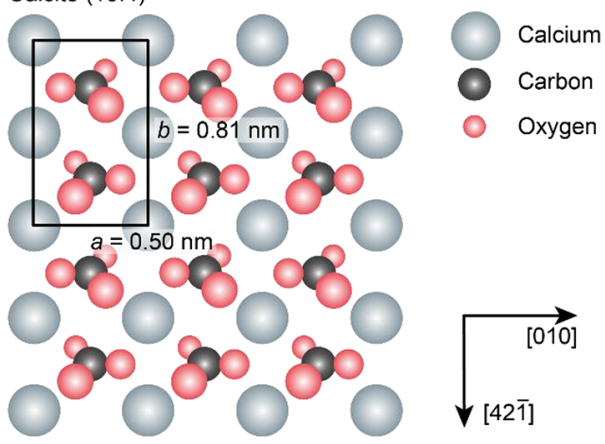

(b) Tetraphosphonates

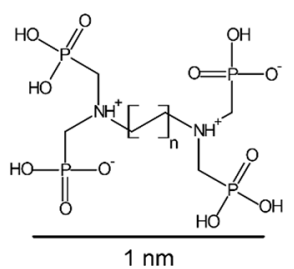

(c) Diphosphonates

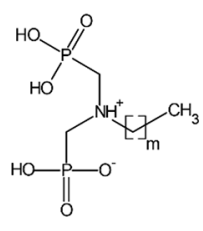

Figure 1. (a) Model of the calcite (10.4) cleavage plane. (b) Schematic structure of the tetraphosphonates. We study molecules with a number of methylene spacing groups of $n=1,3,6$. (c) Schematic structure of the diphosphonates. Here, the number of methylene spacing groups equals $m=1,5,11$. The scale bar in (b) applies to all subfigures. organophosphonate molecules the difference in the number of functional end groups, which consists of phosphonic acid $\left(-\mathrm{PO}_{3} \mathrm{H}_{2}\right)$ groups connected via a tertiary amine ( $\left.\mathrm{R}-\mathrm{N}-\left(\mathrm{CH}_{2}\right)_{2}\right)$ group. The tetraphosphonate molecules possess two aminobis(methylenephosphonate) functional ends (Figure 1b), and the diphosphonate molecules only one identical aminobis(methylenephosphonate) functional end (Figure 1c), respectively. Finally, we systematically vary for all molecules the solution $\mathrm{pH}$ to elucidate the $\mathrm{pH}$ dependence of the surface restructuring process of calcite (10.4) in the presence of organophosphonate molecules.

We find that, independent of the solution $\mathrm{pH}$, all six organophosphonate molecules significantly restructure the (10.4) surface of calcite by the formation of characteristically shaped etch pits. This observation indicates a general property of molecules with functional ends consisting of phosphonate groups connected via a tertiary amine group to enable surface restructuring of the calcite (10.4) cleavage plane. The number of phosphonate end groups alone seems to exert no influence on the ability of the molecules to restructure the calcite (10.4) surface; however, it seems to determine decisively the resulting surface morphology. For the three tetraphosphonate molecules, we observe characteristic olive-shaped etch pits, whereas, for the diphosphonate molecules, a triangular etch pit geometry is predominant on the calcite (10.4) cleavage plane. The results of the surface restructuring within each group of organo-

Table 1. Names, Abbreviations and Schematic Structures for the Organophosphonate Molecules ${ }^{a}$

\begin{tabular}{|c|c|c|}
\hline Additive Name & $\begin{array}{c}\text { Additive } \\
\text { Abbreviation }\end{array}$ & Additive Structure \\
\hline Ethylenediamine-tetrakis(methylenephosphonic acid) & EDTMP-C ${ }_{2}-\mathrm{T}$ & \\
\hline Hexamethylenediamine-tetrakis(methylenephosphonic acid) & HDTMP-C $6-T$ & \\
\hline Dodecamethylenediamine-tetrakis(methylenephosphonic acid) & DDTMP-C $12-T$ & \\
\hline Ethylamine-bis(methylenephosphonic acid) & EABMP-C ${ }_{2}-\mathrm{D}$ & \\
\hline n-Hexamethylamine-bis(methylenephosphonic acid) & HABMP-C $6-D$ & \\
\hline n-Dodecamethylamine-bis(methylenephosphonic acid) & DABMP-C $_{12}-\mathrm{D}$ & \\
\hline
\end{tabular}

${ }^{a}$ The abbreviation includes the acronym for the name, the number of methylene spacing groups $\left(\mathrm{C}_{x}\right)$, as well as a labeling for the number of phosphonic acid end groups. $\mathrm{T}$ denotes tetra for the four phosphonic acid groups in the tetraphosphonates, and $\mathrm{D}$ denotes $d i$ for the two phosphonic acid groups in the diphosphonates. 

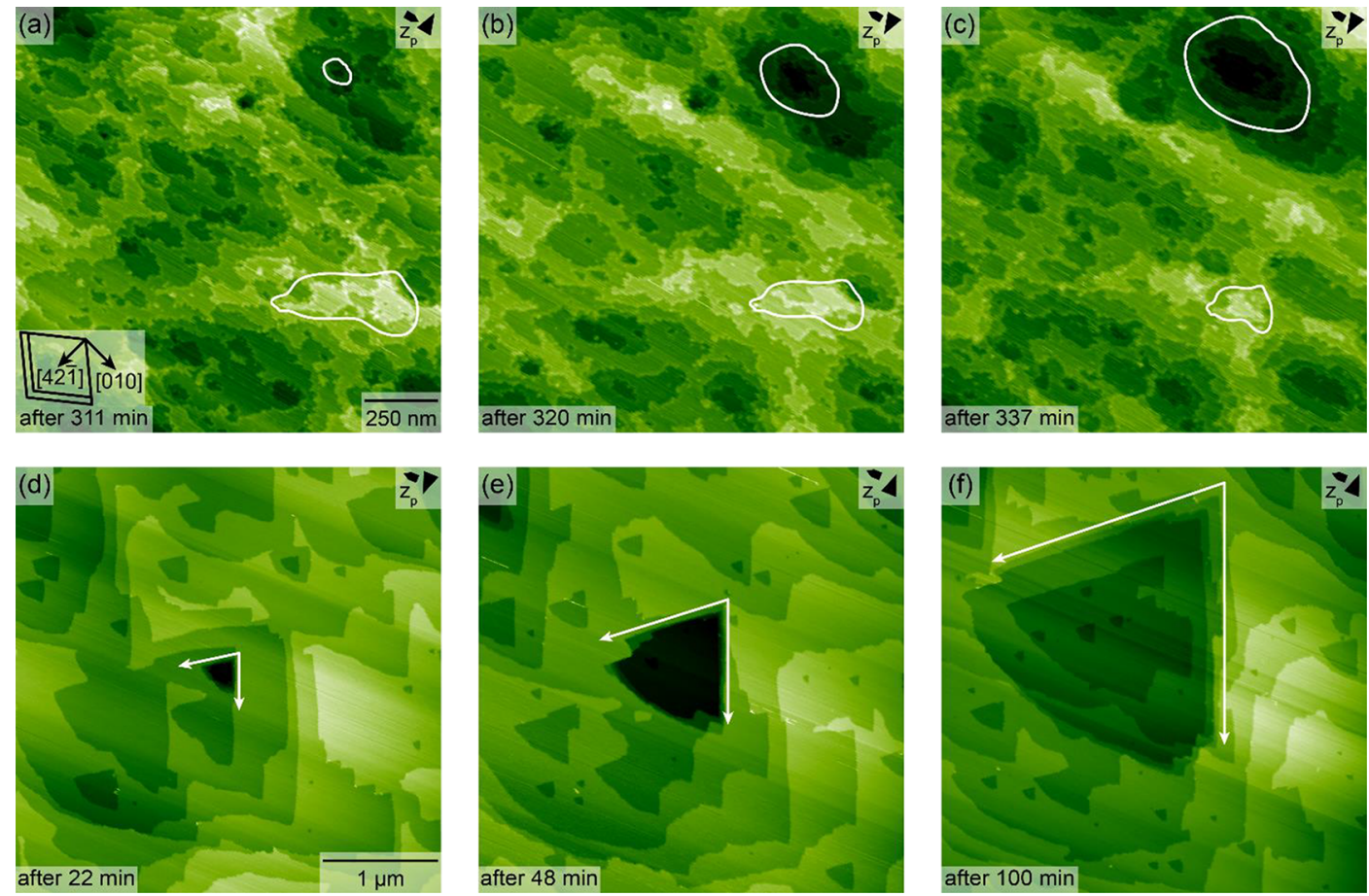

Figure 2. Representative AFM image series of a calcite (10.4) surface in the presence of the organophosphonate molecules demonstrating calcite dissolution and etch pit formation. Images (a) $-(\mathrm{c})$ are taken in the presence of $0.37 \mu \mathrm{M}$ EDTMP- $\mathrm{C}_{2}-\mathbf{T}$ at a pH of 3.1. A rough and uneven calcite (10.4) surface with predominant etch pits and less distinct terraces is found. Perimeters of a shrinking calcite terrace and a growing etch pit are exemplarily marked by white lines. The scale bar in image (a) applies to all images in the series $(a-c)$. Images $(d)-(f)$ are taken in the presence of $258 \mu \mathrm{M}$ EABMP- $\mathrm{C}_{2}-\mathrm{D}$ at a $\mathrm{pH}$ of 6.7. Here, the area of distinct calcite terraces is larger compared to image series $(\mathrm{a}-\mathrm{c})$. The dimension of one dominant growing etch pit is marked by white arrows. The scale bar in image (d) applies to all images in the series (d-f). The images color scale represents a height difference of $3.3 \mathrm{~nm}$ (a, e), $4.3 \mathrm{~nm}$ (b), $5.0 \mathrm{~nm}$ (c), $3.5 \mathrm{~nm}$ (d), and $2.8 \mathrm{~nm}(\mathrm{f})$.

phosphonate molecules are independent of the spacing between the functional ends, revealing that the size of an organophosphonate molecule does not have an influence on the dissolution process of calcite (10.4) and only the presence of at least one functional end plays a decisive role.

\section{MATERIALS AND METHODS}

Organophosphonate Synthesis. Ethylenediamine (99\%), 1,6diaminohexane (>98\%), 1,12-diaminododecane (>98\%), ethylamine (70\%), $n$-hexylamine (99\%), and $n$-dodecylamine (97\%) are purchased from Alfa Aesar; formaldehyde (36.5\% aqueous solution) is purchased from Riedel-de Haen and phosphorus acid (99\%) as well as hydrochloric acid (37\% aqueous solution) are purchased from Sigma-Aldrich. The reactants are all used without further purification. All organophosphonic acid molecules are synthesized via the Mannich-type (Irani-Moedritzer) reaction. In principle, this reaction allows the clean transformation of a primary amine to an amino-bis(methylenephosphonic acid) moiety. Literature procedures are followed. ${ }^{19-21}$ All organophosphonic acids are isolated as high-purity solids in $>50 \%$ yields, except for EDTMP- $\mathbf{C}_{2}-\mathbf{T}$, which is kept dissolved in water and used as a $25.4 \% \mathrm{w} / \mathrm{w}$ stock solution.

Solution Preparation. Pure water $(18.2 \mathrm{M} \Omega \cdot \mathrm{cm})$ is produced from a Merck Millipore purification setup. Hydrochloric acid $(\mathrm{HCl}$, 0.1 and $1 \mathrm{M})$ and sodium hydroxide $(\mathrm{NaOH}, 0.1$ and $1 \mathrm{M})$ standard solutions are purchased from Carl Roth $\mathrm{GmbH} \& \mathrm{Co}$. KG and used to adjust the $\mathrm{pH}$ of the solutions.

Instrumentation. All $\mathrm{pH}$ measurements are conducted using a Schott laboratory $\mathrm{pH}$ meter (CG 842) equipped with a BlueLine $\mathrm{pH}$ electrode (Schott Instruments, $18 \mathrm{pH}$ ). The $\mathrm{pH}$ electrode is calibrated weekly utilizing buffer standard solutions with a $\mathrm{pH}$ value of 4 and 7 (HANNA instruments, type Hi6004 and Hi6007).

In Situ Dynamic Atomic Force Microscopy. For all measurements, we use calcite crystals with a sample size of $4 \times 4 \mathrm{~mm}^{2}$ purchased from Korth Kristalle $\mathrm{GmbH}$. Prior to each experiment, a calcite crystal is freshly cleaved and cleaned under a nitrogen flow. The measurements are conducted at a constant temperature of $28{ }^{\circ} \mathrm{C}$ with a commercial atomic force microscope (AFM) from Bruker Corporation (MultiMode V with Nanoscope V controller) that has been modified for high-resolution imaging in liquid environment. ${ }^{22,23}$ Unless otherwise stated, all AFM images shown here are taken using the frequency modulation (FM) mode in a liquid cell from Bruker Nano Surfaces Division, with gold-coated and p-doped silicon cantilevers (PPP-NCHAuD, Nanosensors and Tap300GD-G, BudgetSensors). The cantilevers possess a typical eigenfrequency of $100-150 \mathrm{kHz}$ in liquids and a spring constant of $\sim 40 \mathrm{~N} / \mathrm{m}$. Initially performed high-resolution measurements enabled atomic resolution of the calcite (10.4) substrate surface, but at the same time, no adsorbed molecular structures on calcite (10.4) step edges or terraces could be observed. As we focus in this study on the dissolution process of calcite (10.4) on a large scale, especially looking at etch pit sizes and shapes, we concentrate here on AFM images with $\mu \mathrm{m}$ size. For all in situ AFM experiments, the oscillation amplitude of the cantilever is kept constant at $1 \mathrm{~nm}$. In all AFM images displayed here, the slow and fast scan direction, as well as the measured channel $\left(z_{\mathrm{p}}\right.$ is the relative piezo displacement) are shown in the schematics in the upper right corner.

Measurement Conditions. We conduct all in situ AFM measurements in an undersaturated solution, with respect to the solubility of calcite. The solution only contains pure water, the solute organophosphonate molecule, and, depending on the starting conditions, hydrochloric acid or sodium hydroxide, respectively. An immersed calcite crystal in this undersaturated solution dissolves at all times, independent of the $\mathrm{pH}$ and until reaching the dynamic carbonate equilibrium. During calcite dissolution, calcium $\left(\mathrm{Ca}^{2+}\right)$ and carbonate $\left(\mathrm{CO}_{3}{ }^{2-}\right)$ ions are released from the surface continuously, the latter causing the $\mathrm{pH}$ of the surrounding solution to converge to a value of around $8.3,{ }^{24}$ corresponding to the carbonate equilibrium. As we observe a continuously dissolving calcite (10.4) surface within the 

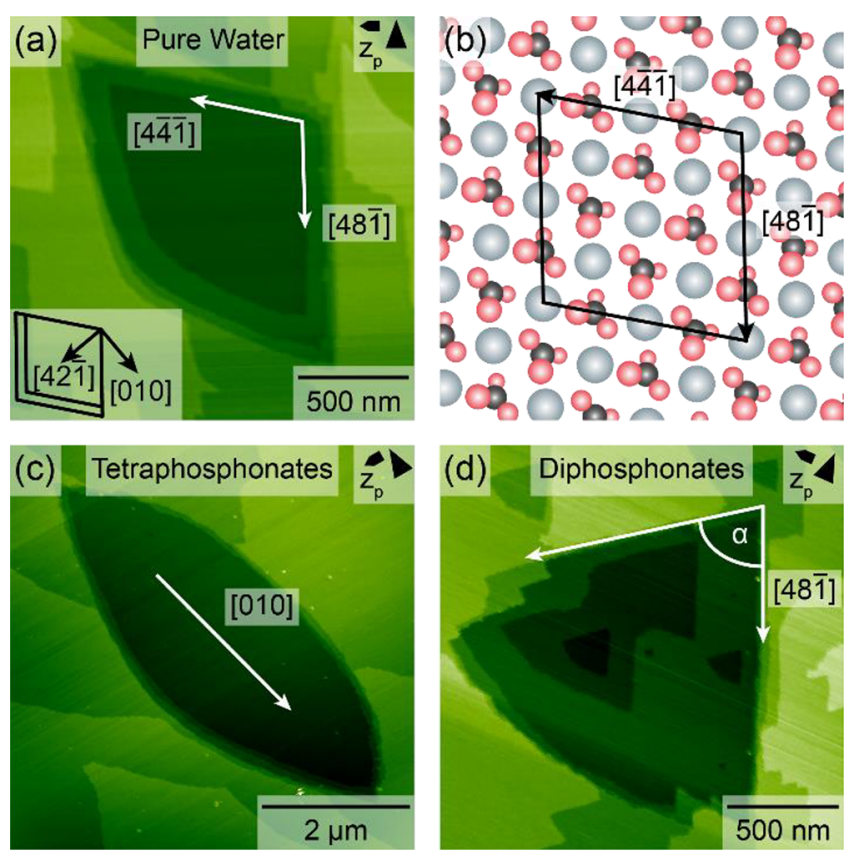

Figure 3. Etch pit geometries observed on the calcite (10.4) surface in the absence and presence of the organophosphonate molecules. (a) Amplitude modulation atomic force microscopy (AM-AFM) image of the calcite (10.4) surface in pure water showing characteristic rhombohedral etch pits. (b) Model of the calcite (10.4) surface illustrating the etch pit termination by the thermodynamically most stable step edges running along the $[4 \overline{41}]$ and $[48 \overline{1}]$ directions. (c) Characteristic olive-shaped etch pit in the presence of the three tetraphosphonate molecules EDTMP- $\mathrm{C}_{2}-\mathrm{T}$, HDTMP- $\mathrm{C}_{6}-\mathrm{T}$, and DDTMP-C $\mathbf{C}_{12}-\mathrm{T}$. The long diagonal of the etch pit is running along the $[010]$ direction, the short diagonal along the $[42 \overline{1}]$ direction. The obtuse step edge sides are rounded similarly to the one in the etch pit in (a). (d) A characteristic triangular etch pit geometry is found when the diphosphonate molecules EABMP- $\mathbf{C}_{2}-\mathbf{D}$, HABMP-C $_{6}-\mathbf{D}$, and DABMP- $\mathbf{C}_{12}-\mathrm{D}$ are present. The etch pits observed here only show the $[48 \overline{1}]$ directions as one of the usually seen acute step edges directions. The angle $\alpha$ to the other acute edge is measured to be $75^{\circ}$. The obtuse step edge side is slightly rounded too. The images color

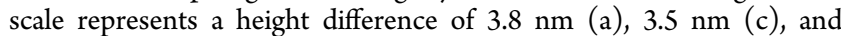
$3.0 \mathrm{~nm}(\mathrm{~d})$.

measuring time of the experiments, we can conclude that the surrounding solution is still undersaturated and that all images are taken at nonequilibrium conditions. The small injection volume (approximately $0.3 \mathrm{~mL}$ ) of the liquid cell disables $\mathrm{pH}$ measurements during and after the in situ AFM experiments. Therefore, all $\mathrm{pH}$ values stated in this study correspond to the initial $\mathrm{pH}$ of the solution, which is adjusted and measured prior to the injection into the liquid cell. Furthermore, as the used liquid cell is open to air, the solution evaporates undoubtedly at all times during the in situ AFM experiment. Hence, this evaporation increases the concentration of all components in the solution. We note that the indicated organophosphonate concentrations also refer to the initial concentrations as prepared.

\section{RESULTS AND DISCUSSION}

We study aqueous organophosphonate solutions with additive concentration ranging from $0.19 \mu \mathrm{M}$ up to $309 \mu \mathrm{M}$. For all additives, we find that a dissolving calcite (10.4) surface restructures under shrinkage of calcite terraces and the formation of characteristically shaped etch pits (Figure 2). Compared to a calcite (10.4) surface dissolving in pure water (in the absence of additives), the calcite (10.4) surface appears to be much more rough and uneven in the presence of the three tetraphosphonate molecules (Figure $2 \mathrm{a}-\mathrm{c}$ ). We observe irregular-shaped calcite (10.4) terraces and several, but small, etch pits. During the experiment, these etch pits grow mainly in size while exposed calcite terraces vanish almost completely. For all three tetraphosphonate molecules (EDTMP- $\mathrm{C}_{2}-\mathrm{T}$, HDTMP- $\mathrm{C}_{6}-\mathrm{T}$, and DDTMP- $\left.\mathrm{C}_{12}-\mathrm{T}\right)$, the very same restructured surface morphology of calcite (10.4) is revealed. This indicates a general property for the group of tetraphosphonate molecules to be able to restructure calcite (10.4) during dissolution. Therefrom, the spacing between the functional ends seems to have no influence on the surface restructuring process as no differences between 2, 6, and 12 separating methylene groups are observed.

For the three diphosphonate molecules (EABMP- $\mathbf{C}_{2}-\mathbf{D}$, HABMP- $\mathrm{C}_{6}-\mathrm{D}$, and DABMP-C $\mathrm{C}_{12}-\mathrm{D}$ ), a very similar situation can be found during calcite dissolution. We also observe a restructured calcite (10.4) surface, however, compared to the tetraphosphonate molecules, now with a larger area of distinct terraces and triangular-shaped etch pits (Figure $2 \mathrm{~d}-\mathrm{f}$ ). Here, during the course of the experiment, the etch pits also grow in size and depth as the confining step edges retreat. However, the calcite (10.4) substrate appears to be less rough and uneven as compared to when the tetraphosphonate molecules are present. Variation of the spacing between the functional ends within the group of diphosphonate molecules (i.e., the length of the alkyl side chain) again shows no difference in the surface restructuring of a dissolving calcite (10.4) surface. This finding also points toward a general property for diphosphonate molecules to restructure calcite (10.4) during dissolution.

As all six organophosphonate molecules studied here show the very same influence on calcite (10.4) dissolution, we can conclude that the existence of at least one functional end (two methylenephosphonate groups connected via a tertiary amine group) enables calcite (10.4) surface restructuring. Furthermore, as we can see qualitative differences in the surface morphology induced by tetra- and diphosphonate molecules, but no differences within each group, we can deduce that the number of functional end groups has a significant influence, whereas the spacing between the functional ends seems not to play an important role.

Etch Pit Geometries on Calcite (10.4). The dissolution process of calcite (10.4) in pure water is characterized by the formation of rhombohedral etch pits (Figure 3a). These etch pits are terminated by the thermodynamically most stable step edges running along the $[4 \overline{41}]$ and $[48 \overline{1}]$ directions (Figure 3b). All four step edges of an etch pit are neutral because of an alternating arrangement of calcium ions and carbonate groups. Tilting of the carbonate groups in the calcite (10.4) surface structure results in two different edges pits sides, namely, acute and obtuse. The two obtuse step edge sides are known to exhibit a more rounded shape, resulting in the asymmetric etch pit appearance in Figure 3a. ${ }^{25-27}$

In the presence of the three tetraphosphonate molecules EDTMP-C - -T, HDTMP-C ${ }_{6}-T$, and DDTMP-C ${ }_{12}$-T, etch pits with an olive shape are observed all over the calcite (10.4) surface (Figure 3c). The geometry of the olive-shaped etch pits is similar to etch pits on the calcite (10.4) substrate in pure water. The long diagonal is also running along the [010] direction; likewise, the short diagonal is running along the [421] direction. The two obtuse step edge sides are rounded in a similar way as it is observed in the asymmetric etch pit appearance in pure water. In contrast to the etch pit shape in pure water, the two acute edges of the olive-shaped etch pit are modified, resulting in a very symmetric etch pit geometry. 
Scheme 1. Protonation/Deprotonation Sequence for EDTMP-C $-\mathrm{T}$, Showing Eight Experimentally Detected Species ${ }^{a}$<smiles>O=P([O-])(O)C[NH+](CC[NH+](CP(=O)([O-])O)CP(=O)([O-])O)CP(=O)([O-])O</smiles>

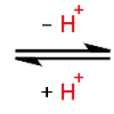

$\log K_{\mathrm{a}}=1.3$

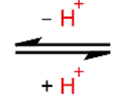

$\log K_{\mathrm{a}}=5.1$

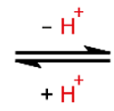

$\log K_{a}=7.9$

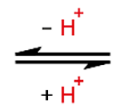

$\log K_{\mathrm{a}}=13.8$<smiles>O=P([O-])(O)C[NH+](CC[NH+](CP(=O)([O-])O)CP(=O)([O-])O)CP(=O)([O-])O</smiles>

$-\mathrm{H}^{+} \|+\mathrm{H}^{+} \quad \log \mathrm{K}_{\mathrm{a}}=3.0$<smiles>O=P([O-])([O-])C[NH+](CC[NH+](CP(=O)([O-])O)CP(=O)([O-])O)CP(=O)([O-])O</smiles><smiles>O=P([O-])([O-])C[NH+](CC[NH+](CP(=O)([O-])[O-])CP(=O)([O-])[O-])CP(=O)([O-])[O-]</smiles>

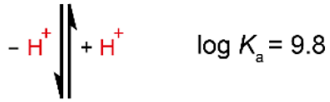<smiles>O=P([O-])([O-])CN(CCN(CP(=O)([O-])[O-])CP(=O)([O-])[O-])CP(=O)([O-])[O-]</smiles><smiles>O=P([O-])([O-])CN(CC[NH+](CP(=O)([O-])[O-])CP(=O)([O-])[O-])CP(=O)([O-])[O-]</smiles>

${ }^{a^{a}}$ The stepwise deprotonation behavior, starting from the three-fold deprotonated $\left(\mathbf{H}_{7}\right.$ EDTMP- $\left.\mathbf{C}_{2}-\mathbf{T}^{-}\right)$species to the fully deprotonated (EDTMP$\mathrm{C}_{2}-\mathrm{T}^{8-}$ ) species, is displayed from left to right and top to bottom. Values for the logarithmic acid dissociation constant (log $K_{\mathrm{a}}$ ) for each protonation/deprotonation step are provided. ${ }^{29}$ Relevant protons for each protonation/deprotonation step are highlighted in red.

For the three diphosphonate molecules EABMP-C $\mathbf{C}_{2}-\mathbf{D}$, HABMP- $\mathrm{C}_{6}-\mathrm{D}$, and DABMP-C $12-\mathrm{D}$, we find etch pits with a predominant triangular etch pit geometry (Figure $3 \mathrm{~d}$ ). These etch pits only show one of the commonly seen thermodynami-

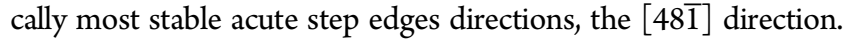
The obtuse step edge side is slightly rounded too and, therefore, comparable to the etch pit curvature for pure water and for the presence of the tetraphosphonates. The pronounced angle in the acute step edge corner is measured to be $75^{\circ}$.

pH-Independent Dissolution Process. Organophosphonic acids produce a plethora of chemical species in aqueous solutions, depending on the $\mathrm{pH} .{ }^{28}$ Popov et al. ${ }^{29}$ have summarized a large portion of the available literature on critical stability constants for a number of phosphonic acids. On the basis of the reported data, we draw Scheme 1, illustrating the protonation/ deprotonation of EDTMP- $\mathrm{C}_{2}-\mathrm{T}$, exemplarily for the three tetraphosphonates, as well as Scheme 2 showing the protonation/ deprotonation of EABMP-C $\mathbf{C}_{2}-\mathbf{D}$, exemplarily for the three diphosphonates.

Such data and related speciation diagrams ${ }^{30}$ can be very useful in interpreting experimental results, particularly for mineral scale inhibition $^{31}$ and decalcification of biominerals ${ }^{32,33}$ but should be used with caution due to the different experimental conditions employed in measuring the $\mathrm{p} K_{\mathrm{a}}$ 's of the phosphonic acids. 
Scheme 2. Protonation/Deprotonation for EABMP-C - D, Showing Five Experimentally Detected Species ${ }^{a}$<smiles>CC[NH+](CCP(=O)([O-])O)CP(=O)(O)O</smiles><smiles>CC[NH+](CP(=O)([O-])O)CP(=O)([O-])O</smiles>

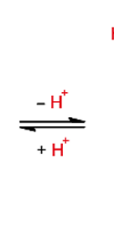<smiles>CC[NH+](CP(=O)([O-])[O-])CP(=O)([O-])O</smiles><smiles>CCN(CP(=O)([O-])[O-])CP(=O)([O-])[O-]</smiles><smiles>C=C[NH+](CC)CP(=O)([O-])[O-]</smiles>

$a_{\text {The stepwise deprotonation behavior, starting from the neutral }}$ $\left(\mathbf{H}_{4}\right.$ EABMP-C $\left.2-\mathbf{D}\right)$ species to the fully deprotonated (EABMP-C $\mathbf{2}^{-}$ $\mathrm{D}^{4-}$ ) species. Relevant protons for each protonation/deprotonation step are highlighted in red.

To study the $\mathrm{pH}$ dependence of calcite (10.4) surface restructuring in the presence of the organophosphonate molecules, we perform in situ AFM experiments with solution $\mathrm{pH}$ values ranging from 2.6 up to 11.7. The results for the measurements with varying solution $\mathrm{pH}$ are illustrated in Figure 4. Here, we show representative results for the tetraphosphonate EDTMP-C $\mathrm{C}_{2}-\mathrm{T}$ at solution $\mathrm{pH}$ values of 4.1, 8.2, and 11.7 (Figure $4 \mathrm{a}-\mathrm{c}$ ), and for the diphosphonate EABMP- $\mathrm{C}_{2}-\mathrm{D}$ at solution $\mathrm{pH}$ values of $3.5,5.7$, and 9.5 in Figure $4 \mathrm{~d}-\mathrm{f}$. We find no significant differences in the surface restructuring, regardless of the $\mathrm{pH}$ value or the molecule studied. We observe for both families of organophosphonate molecules the very same etch pit shape (olive for the tetraphosphonate and triangular for the diphosphonate molecules) as the result of the dissolution process, independent of solution $\mathrm{pH}$. This observation indicates that the surface restructuring process seems to be insensitive against variations in both factors, i.e., structural differences due to the alkyl spacing between the functional ends and different protonation/deprotonation states caused by the solution $\mathrm{pH}$. The $\mathrm{pH}$ independence of calcite (10.4) surface restructuring has been recently also observed in in situ AFM studies in the presence of organic dye molecules $^{34}$ and, hence, might indicate a more general surface restructuring mechanism in the presence of chemical additives.

\section{SUMMARY AND CONCLUSION}

Herein, we systematically study the impact of six different organophosphonate molecules, three tetraphosphonates (EDTMP-C $2-T$, HDTMP-C 6 -T, and DDTMP-C ${ }_{12}-\mathrm{T}$ ) and three diphosphonates (EABMP-C $-\mathbf{D}, \mathbf{H A B M P}-\mathrm{C}_{6}-\mathrm{D}$, and DABMP-C C $\left._{12}-\mathrm{D}\right)$ on the dissolution process of calcite (10.4) using in situ dynamic AFM. For each molecule, a pronounced surface restructuring is observed, resulting in the formation of characteristically shaped etch pits for each group of organophosphonate molecules. From that, we can conclude that the existence of at least one functional end (two phosphonate groups connected via methylene linkers to a tertiary amine group) is sufficient to enable calcite (10.4) surface restructuring. This observation points toward a general property of organophosphonate molecules to alter and restructure the (10.4) surface of calcite during dissolution. Furthermore, the difference in the number of functional phosphonate end groups (four for
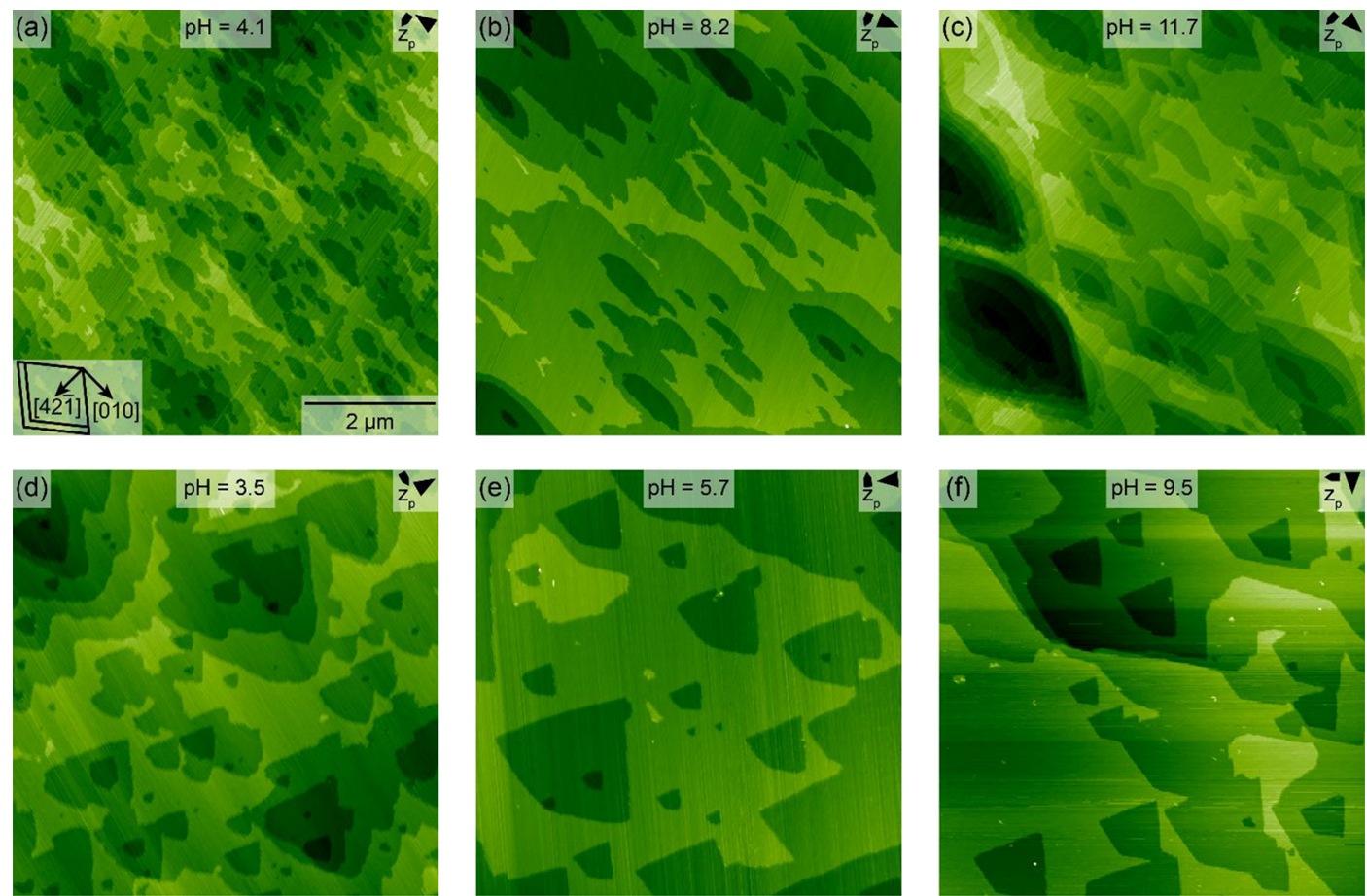

Figure 4. Representative AFM images demonstrating the $\mathrm{pH}$ independence of the surface restructuring of calcite (10.4) in the presence of the organophosphonate molecules. The images (a) - (c) are taken in the presence of $0.19 \mu \mathrm{M}$ EDTMP- $\mathbf{C}_{2}-\mathbf{T}$ at solution $\mathrm{pH}$ values of $4.1,8.2$ and 11.7 , respectively. The images (d) and (f) are taken in the presence of $309 \mu \mathrm{M}$ EABMP-C $\mathbf{C}_{2}-\mathbf{D}$, image (e) in the presence of $258 \mu \mathrm{M}$ EABMP-C $\mathbf{C}_{2}-\mathbf{D}$ at solution $\mathrm{pH}$ values of 3.5, 5.7, and 9.5, respectively. The scale bar in (a) applies to all images. The images color scale represents a height difference of $3.0 \mathrm{~nm}$ (a), $2.5 \mathrm{~nm}(\mathrm{~b}, \mathrm{~d}), 5.0 \mathrm{~nm}$ (c), $3.3 \mathrm{~nm}$ (e), and $2.1 \mathrm{~nm}(\mathrm{f})$. 
the tetraphosphonates and two for the diphosphonates) decisively determines the resulting surface morphology. We observe olive-shaped etch pits for the tetraphosphonate and triangular-shaped ones for the diphosphonate molecules. In contrast to the number of functional end groups, changing the spacing between the functional ends through a variation of the number of methylene groups $(2,6$, and 12$)$ has no influence on the dissolution process of calcite (10.4). For all three tetraphosphonate as well as for the three diphosphonate derivatives, we observe the very same etch pit geometry, respectively. Finally, the dissolution process of calcite (10.4) in the presence of each of phosphonate molecules is independent of solution $\mathrm{pH}$ and, therefore, not affected by the protonation/deprotonation state of the molecules. The surface restructuring process of calcite (10.4) during dissolution in the presence of the organophosphonate molecules studied here appears to be very robust against variations in both, additive molecular structure and solution $\mathrm{pH}$. Although precise information on the interaction of the phosphonate group with the calcite surface at the molecular level cannot be drawn from AFM studies, it is well established that the doubly deprotonated $\mathrm{R}-\mathrm{PO}_{3}{ }^{2-}$ group interacts much more strongly with the calcite surface than the singly deprotonated $\mathrm{R}-\mathrm{PO}_{3} \mathrm{H}^{-}$group. ${ }^{7}$ This is consistent with the $\mathrm{pH}$-independent restructuring process observed for all organophosphonate additives. Furthermore, the second additive side moiety (a second amino-bis(methylenephosphonate) group for the tetraphosphonates and an alkyl group for the diphosphonates) does not seem to directly interact with the surface of calcite (10.4). However, it may indirectly influence the interaction of the entire molecule by creating a hydrophilic (for tetraphosphonates) or a hydrophobic (for diphosphonates) microenvironment on the calcite surface. The structural differences in the non-interacting side groups between tetraphosphonates and diphosphonates are consistent with the morphology of the etch pits observed. The important observation that, within the same family, the side chain length does not seem to influence the restructuring process confirms that one bis(methylenephosphonate) moiety alone is necessary for the process to occur.

\section{AUTHOR INFORMATION}

\section{Corresponding Author}

*E-mail: nalbach@uni-mainz.de.

\section{ORCID $\odot$}

Martin Nalbach: 0000-0003-0045-7548

Konstantinos D. Demadis: 0000-0002-0937-8769

Angelika Kühnle: 0000-0003-1214-1006

\section{Author Contributions}

The manuscript was written through contributions of all authors. All authors have given approval to the final version of the manuscript.

Notes

The authors declare no competing financial interest.

\section{ACKNOWLEDGMENTS}

A.K. acknowledges financial support by the German Research Foundation through project KU1980/7-1, and K.D.D. thanks the University of Crete for financial support through Research Grant KA 3517.

\section{ABBREVIATIONS}

EDTMP- $\mathrm{C}_{2}$-T, ethylenediamine-tetrakis(methylenephosphonic acid)
HDTMP- $\mathrm{C}_{6}-\mathrm{T}$, hexamethylenediamine-tetrakis (methylenephosphonic acid)

DDTMP-C ${ }_{12}-\mathrm{T}$,Dodecamethylenediamine-tetrakis(methylenephosphonic acid)

EABMP- $\mathrm{C}_{2}-\mathrm{D}$,ethylamine-bis(methylenephosphonic acid)

HABMP- $\mathrm{C}_{6}-\mathrm{D}, n$-hexamethylamine-bis (methylenephosphonic acid)

DABMP-C ${ }_{12}-\mathrm{D}, n$-dodecamethylamine-bis(methylenephosphonic acid)

AFM,atomic force microscopy

\section{REFERENCES}

(1) Murugavel, R.; Choudhury, A.; Walawalkar, M. G.; Pothiraja, R.; Rao, C. N. R. Metal Complexes of Organophosphate Esters and OpenFramework Metal Phosphates: Synthesis, Structure, Transformations, and Applications. Chem. Rev. 2008, 108, 3549-3655.

(2) Dean, J. A. Lange's Handbook of Chemistry and Physics, 15th ed.; McGraw Hill Inc.: New York, 1999.

(3) Demadis, K. D. Chemistry of Organophosphonate Scale Inhibitors, Part 4: Stability of Amino-tris-(Methylene Phosphonate) Towards Degradation by Oxidizing Biocides. Phosphorus, Sulfur Silicon Relat. Elem. 2006, 181, 167-176.

(4) Demadis, K. D.; Stavgianoudaki, N. Structural Diversity in Metal Phosphonate Frameworks: Impact on Applications. In Metal Phosphonate Chemistry: From Synthesis to Applications; The Royal Society of Chemistry Publishing: Cambridge, U.K., 2012; Chapter 14, pp 438-492.

(5) Demadis, K. D.; Baran, P. Chemistry of organophosphonate scale growth inhibitors: Two-dimensional, layered polymeric networks in the structure of tetrasodium 2-hydroxyethyl-amino-bis(methylenephosphonate). J. Solid State Chem. 2004, 177, 4768-4776.

(6) Ruiz-Agudo, E.; Di Tommaso, D.; Putnis, C. V.; de Leeuw, N. H.; Putnis, A. Interactions between Organophosphonate-Bearing Solutions and (1014) Calcite Surfaces: An Atomic Force Microscopy and FirstPrinciples Molecular Dynamics Study. Cryst. Growth Des. 2010, 10, 3022-3035.

(7) El Malti, W.; Laurencin, D.; Guerrero, G.; Smith, M. E.; Mutin, P. $\mathrm{H}$. Surface modification of calcium carbonate with phosphonic acids. J. Mater. Chem. 2012, 22, 1212-1218.

(8) Wang, L.; Qin, L.; Putnis, C. V.; Ruiz-Agudo, E.; King, H. E.; Putnis, A. Visualizing Organophosphate Precipitation at the CalciteWater Interface by in Situ Atomic-Force Microscopy. Environ. Sci. Technol. 2016, 50, 259-268.

(9) Akyol, E.; Öner, M.; Barouda, E.; Demadis, K. D. Systematic Structural Determinants of the Effects of Tetraphosphonates on Gypsum Crystallization. Cryst. Growth Des. 2009, 9, 5145-5154.

(10) Barouda, E.; Demadis, K. D.; Freeman, S. R.; Jones, F.; Ogden, M. I. Barium Sulfate Crystallization in the Presence of Variable Chain Length Aminomethylenetetraphosphonates and Cations $\left(\mathrm{Na}^{+}\right.$or $\left.\mathrm{Zn}^{2+}\right)$. Cryst. Growth Des. 2007, 7, 321-327.

(11) Wang, L.; Putnis, C. V.; King, H. E.; Hövelmann, J.; RuizAgudo, E.; Putnis, A. Imaging Organophosphate and Pyrophosphate Sequestration on Brucite by in Situ Atomic Force Microscopy. Environ. Sci. Technol. 2017, 51, 328-336.

(12) Orme, C. A.; Noy, A.; Wierzbicki, A.; McBride, M. T.; Grantham, M.; Teng, H. H.; Dove, P. M.; De Yoreo, J. J. Formation of chiral morphologies through selective binding of amino acids to calcite surface steps. Nature 2001, 411, 775-779.

(13) Cölfen, H.; Antonietti, M. Mesocrystals: Inorganic Superstructures Made by Highly Parallel Crystallization and Controlled Alignment. Angew. Chem., Int. Ed. 2005, 44, 5576-5591.

(14) Sonnenberg, L.; Luo, Y.; Schlaad, H.; Seitz, M.; Cölfen, H.; Gaub, H. E. Quantitative Single Molecule Measurements on the Interaction Forces of Poly-(1-glutamic acid) with Calcite Crystals. J. Am. Chem. Soc. 2007, 129, 15364-15371.

(15) Schenk, A. S.; Zlotnikov, I.; Pokroy, B.; Gierlinger, N.; Masic, A.; Zaslansky, P.; Fitch, A. N.; Paris, O.; Metzger, T. H.; Cölfen, H.; et al. Hierarchical Calcite Crystals with Occlusions of a Simple Polyelec- 
trolyte Mimic Complex Biomineral Structures. Adv. Funct. Mater. 2012, 22, 4668-4676.

(16) Sand, K. K.; Pedersen, C. S.; Sjoberg, S.; Nielsen, J. W.; Makovicky, E.; Stipp, S. L. S. Biomineralization: Long-Term Effectiveness of Polysaccharides on the Growth and Dissolution of Calcite. Cryst. Growth Des. 2014, 14, 5486-5494.

(17) Momper, R.; Nalbach, M.; Lichtenstein, K.; Bechstein, R.; Kühnle, A. Stabilization of Polar Step Edges on Calcite (10.4) by the Adsorption of Congo Red. Langmuir 2015, 31, 7283-7287.

(18) Ricci, M.; Segura, J. J.; Erickson, B. W.; Fantner, G.; Stellacci, F.; Voitchovsky, K. Growth and Dissolution of Calcite in the Presence of Adsorbed Stearic Acid. Langmuir 2015, 31, 7563-7571.

(19) Moedritzer, K.; Irani, R. R. The Direct Synthesis of $\alpha$ Aminomethylphosphonic Acids. Mannich-Type Reactions with Orthophosphorous Acid. J. Org. Chem. 1966, 31, 1603-1607.

(20) Hellal, A.; Chafaa, S.; Chafai, N. Synthesis, characterization and computational studies of three $\alpha$-amino-phosphonic acids derivatives from Meta, Ortho and Para aminophenol. J. Mol. Struct. 2016, 1103, $110-124$.

(21) Mady, M. F.; Kelland, M. A. Overview of the Synthesis of Salts of Organophosphonic Acids and Their Application to the Management of Oilfield Scale. Energy Fuels 2017, 31, 4603-4615.

(22) Rode, S.; Stark, R.; Lübbe, J.; Tröger, L.; Schütte, J.; Umeda, K.; Kobayashi, K.; Yamada, H.; Kühnle, A. Modification of a commercial atomic force microscopy for low-noise, high-resolution frequencymodulation imaging in liquid environment. Rev. Sci. Instrum. 2011, 82, 073703.

(23) Adam, H.; Rode, S.; Schreiber, M.; Kobayashi, K.; Yamada, H.; Kühnle, A. Photothermal excitation setup for a modified commercial atomic force microscope. Rev. Sci. Instrum. 2014, 85, 023703.

(24) Harstad, A. O.; Stipp, S. L. S. Calcite dissolution: Effects of trace cations naturally present in Iceland spar calcites. Geochim. Cosmochim. Acta 2007, 71, 56-70.

(25) Liang, Y.; Baer, D. R.; Lea, A. S. Dissolution of $\mathrm{CaCO}_{3}$ (1014) Surface. MRS Online Proc. Libr. 1994, 355, 355-409.

(26) Park, N.-S.; Kim, M.-W.; Langford, S. C.; Dickinson, J. T. Tribological Enhancement of $\mathrm{CaCO}_{3}$ Dissolution during Scanning Force Microscopy. Langmuir 1996, 12, 4599-4604.

(27) Britt, D. W.; Hlady, V. In-Situ Atomic Force Microscope Imaging of Calcite Etch Pit Morphology Changes in Undersaturated and 1-Hydroxyethylidene-1,1-diphosphonic Acid Poisoned Solutions. Langmuir 1997, 13, 1873-1876.

(28) Ichikawa, T.; Sawada, K. Structure and NMR Behavior of Cobalt-(III) Polyamine Complexes of $\alpha, \omega$-Alkylenediamine$N, N, N^{\prime} N^{\prime}$-tetramethylenetetraphosphonate in Aqueous Solution. Bull. Chem. Soc. Jpn. 1997, 70, 2111-2123.

(29) Popov, K.; Rönkkömäki, H.; Lajunen, L. H. J. Critical evaluation of stability constants of phosphonic acids (IUPAC Technical Report). Pure Appl. Chem. 2001, 73, 1641-1677.

(30) Ruiz-Agudo, E.; Rodriguez-Navarro, C.; Sebastián-Pardo, E. Sodium Sulfate Crystallization in the Presence of Phosphonates: Implications in Ornamental Stone Conservation. Cryst. Growth Des. 2006, 6, 1575-1583.

(31) Kofina, A. N.; Demadis, K. D.; Koutsoukos, P. G. The Effect of Citrate and Phosphocitrate On Struvite Spontaneous Precipitation. Cryst. Growth Des. 2007, 7, 2705-2712.

(32) Demadis, K. D.; Anagnostou, Z.; Zhao, H. Novel Calcium Carboxyphosphonate/polycarboxylate Inorganic-Organic Hybrid Materials from Demineralization of Calcitic Biomineral Surfaces. ACS Appl. Mater. Interfaces 2009, 1, 35-38.

(33) Ehrlich, H.; Koutsoukos, P. G.; Demadis, K. D.; Pokrovsky, O. S. Principles of demineralization: Modern strategies for the isolation of organic frameworks. Part II. Decalcification. Micron 2009, 40, 169193.

(34) Nalbach, M.; Klassen, S.; Bechstein, R; Kühnle, A. Molecular Self-Assembly Versus Surface Restructuring During Calcite Dissolution. Langmuir 2016, 32, 9975-9981. 